\title{
Evaluation the Effect of Fibers Addition on Mechanical Properties of Flexible Acrylic Resin
}

\author{
Mr. ZAID EZZAT ABDUL-MAJEED \\ MSc.student \\ Assistant Professor Dr. Israa Mohammed Hummudi \\ Department of Prosthodontic Techologies / College of Health and Medical Technologies \\ Middle Technical University
}

\begin{abstract}
Background: In chemistry the development of polymer has produced another material to poly methyl methacrylate such as epoxy resins, polyamides (nylon), acetyl resins -----etc. All these resins are suited for thermoplastic processing. Polyamide materials are more flexible than the commonly used polymethylmethacrylate. The flexibility of polyamide allows partial dentures to be pressed in one piece including clasps. Glass fibers are the most widely used reinforcing materials forming about $90 \%$ of the reinforcement in resins. The addition of fibers to provisional restorative resin increases tensile strength, fracture toughness and surface hardness.
\end{abstract}

Objective of the study: An evaluation of the surface roughness, modulus of elasticity and tensile strength improvement of flexible denture bases after adding of glass fibers and altering in powder - monomer ratio.

Material and Methods: Eighty samples of flexible acrylic were made and divided into two main groups according to the type of test to be used. Forty samples for surface roughness and forty samples for tensile strength and (modulus of elasticity). Each group is divided into four subgroups according to fibers addition and to the alteration in powder-liquid ratio as follows: group (A) consists of (10 specimens) without the addition of glass fibers and with (3:1) powder- monomer ratio. Group (B) consists of (10 specimens) with addition of glass fibers and with (3:1) powder- monomer ratio, group (C) consists of (10 specimens) without addition of glass fibers and with (2.5:1) powder- monomer ratio and group (D) consists of (10 specimens) with glass fibers and with (2.5:1) powdermonomer ratio. The tensile strength and modulus of elasticity were determined by Instron testing machine at cross speed of $0.5 \mathrm{~mm} / \mathrm{min}$. The T.R 200 device was used to indicate the values of surface roughness specimens before and after finishing and polishing.

Results: In the present study, ANOVA test showed a significant difference at $(P<0.05)$ between all the groups of tensile strength test. Least significant difference( $L S D)$ test showed a non-significant difference at $(P>0.05)$ between most of the tested groups except the groups of 3:1 powder-monomer ratio with and without fibers addition and groups of 3:1 ratio without fibers addition in comparison with the groups of 2.5:1 ratio with fibers addition which showed highly significant . The modulus of elasticity revealed a non-significant difference between all the tested groups at $(P>0.05)$. While there were highly significant difference at $(p<0.01)$ between groups of surface roughness test before and after polishing, except the group of 2.5:1 ratio with and without fibers addition which showed a non-significant difference at $(P>0.05$.).

Conclusion: Conclusion was derived that fibers addition significantly affects tensile strength. The modulus of elasticity was not significantly affected by fibers addition or by powder-monomer ratio. Regarding surface roughness, it was improved after fibers addition and alteration in powder-liquid ratio.

الخمانة

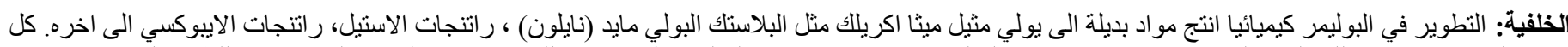

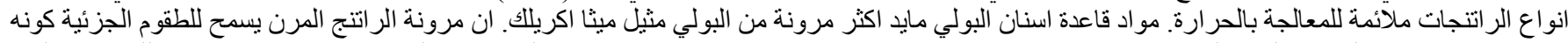

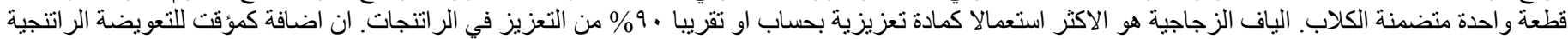

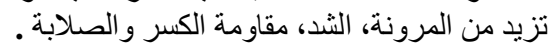

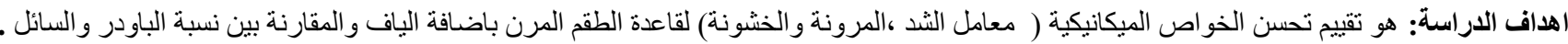

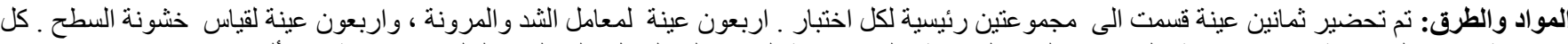

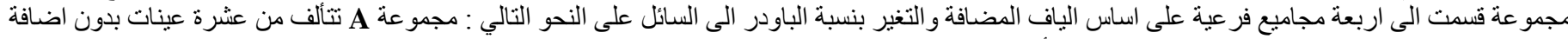

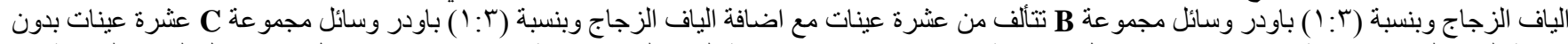

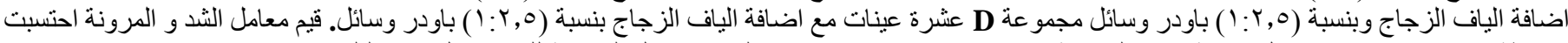

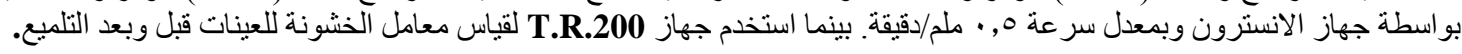

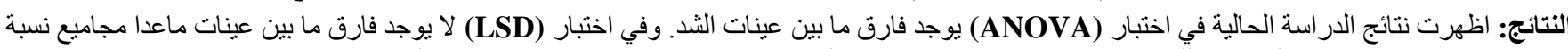

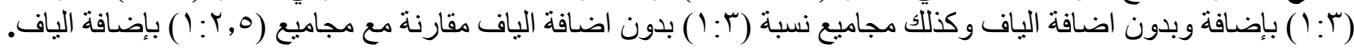

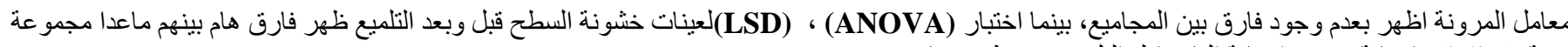

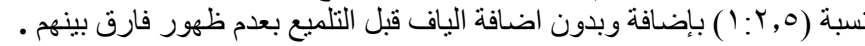

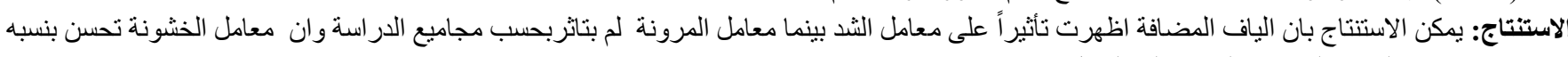
كبيره بعد اضافة الياف على نسبة البادور الى السائل. 


\section{INTRODUCTION}

Favorable denture resin material is needed for constructing long lasting dentures and biologically acceptance (1). Acrylic "poly methyl methacrylate" is widely used denture base materials with numerous advantages, but has poor properties for example fracture due to unsatisfactory impact strength, fatigue resistance, transverse strength and sensitive to allergic (2).

Studies have been done to improve the properties of PMMA. However, nylon material gained attractive attention as a denture base due to many advantages, including: non-metal clasp (esthetic), Toxicological safety to patients allergic to monomer and metals, higher elasticity than heat polymerizing

acrylic and enough strength as a denture base material (3).

The higher nylon elasticity and modeling precision than the heat PMMA accelerate denture retention by utilizing the undercuts of teeth in the denture design, so clasps and problems resulting from metal clasps such as excessive load on teeth, undesirable esthetic properties and allergy to metal can be eliminated (4).

Many techniques are used to improve the mechanical and surface properties of the acrylic resins have been developed. One technique is to substitute PMMA by another base material (e.g. Epoxy resins and polyamide), or the incorporation of a copolymer of rubber within PMMA to raise its impact strength Other options include the use of fiber addition or metallic wire to strengthen the denture base resins. Recently, a great emphasis has been placed on the use of glass fibers for denture reinforcement (5).

Advantages of high properties, stability in the oral environment, wettability, favorable aesthetic qualities and biocompatibility make glass fiber a suitable material for resins reinforcement (6).

The appropriate ratio of polymer to monomer is 3 to $3.5: 1$ by volume or $2.5: 1$ by weight. This ratio is important to control the workability of the mix and the dimensional changes on setting (7).

Mechanical properties such as modulus of elasticity, surface roughness properties are important to characterize flexible materials that are reinforced with glass fibers (8).

This study was designed to evaluate the effect of glass fibers addition on tensile strength (modulus of elasticity) and surface roughness of flexible acrylic resin and the effect of the alteration of powder-liquid ratio on these properties.

\section{METHODS}

\section{Samples grouping}

A total of ( 80 specimens) were prepared from Polyamide flexible acrylic (IMPAK powder and liquid, USA) and divided into two main groups according to the tests that used (forty specimens for tensile strength and modulus of elasticity test, forty specimens for surface roughness test) then each test subdivided into four subgroups according to the fibers addition and different Powder- Monomer ratio as follows:

1- Group A (control): 10 specimens without addition of glass fibers and with 3.1 powder monomer ratio.

2- Group B (experimental): 10 specimens with addition of glass fibers and with 3.1 powdermonomer ratio.

3- Group C (experimental): 10 specimens without addition of glass fibers and with 2.5:1 powder- monomer ratio.

4- Group D (experimental): 10 specimens with addition of glass fibers and with 2.5:1 powdermonomer ratio.

\section{Samples Preparation for tensile test}

For the tensile strength test, 40 flat rectangle shaped specimens were prepared with $(40 \mathrm{~mm}$ length, $10 \mathrm{~mm}$ width and $2 \mathrm{~mm}$ thickness) (9) (Fig.1)

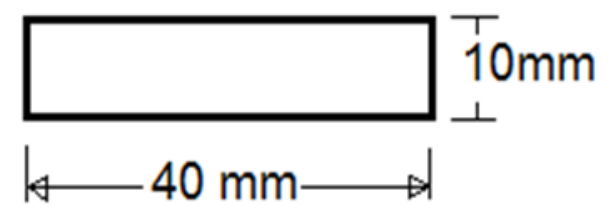

\section{Thickness $=2 \mathrm{~mm}$}

Figure (1): Dimensions of tensile test specimen.

\section{Flexible acrylic samples preparation:-}

Wax plate $(40 \times 10 \times 2 \mathrm{~mm})$ length, width, thickness in dimensions was prepared. $33 \mathrm{ml}$ water and $100 \mathrm{gm}$ powder of stone was mixed according to the manufacturer instructions and poured in the flask, as shown in Fig. (2) 


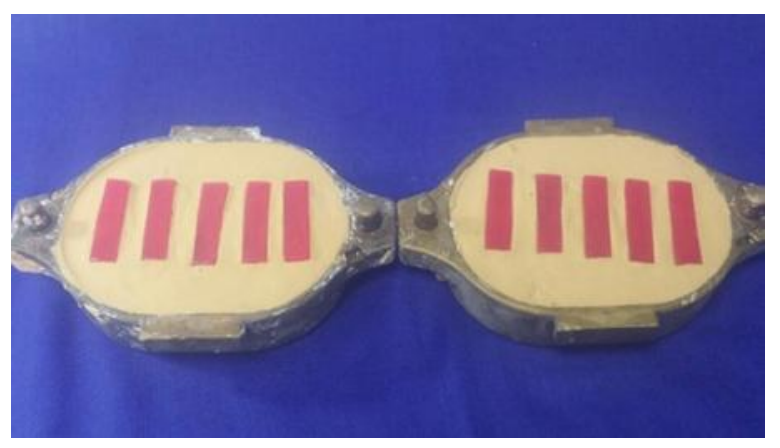

Figure (2): Wax pattern specimen for tensile test.

Before the stone in the lower half of the flask was harden, plate of wax was placed over the stone and the level of the wax would be with the level of the stone (Fig.3).

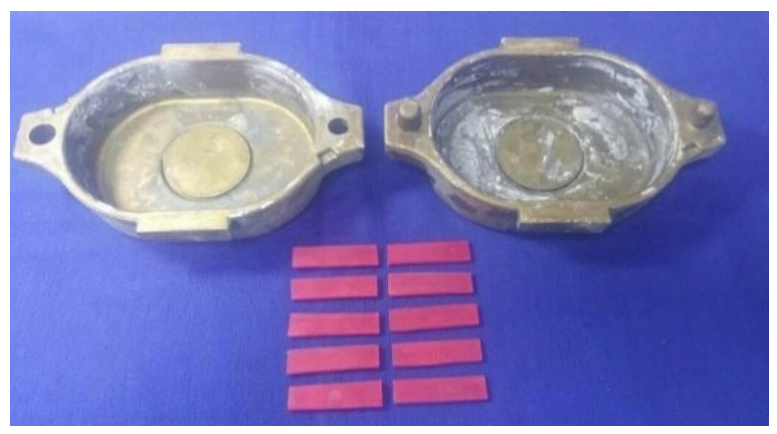

Figure (3): wax Specimens for tensile test in the flask.
The stone was coated with separating medium when reach to initial set. Then a second mix of stone was poured and kept under the hydraulic press. Wax elimination was done after complete setting by immersing the flask for four minutes in boiling water. The flask was opened, washed with boiled water and allowed to cool. The flask was opened and the mold was coated with the separating medium (10)

\section{Proportioning and adding of glass fibers:}

Glass fibers (IMPAK,USA ) were added to the flexible acrylic resin powder using weight/weight $(\mathrm{w} / \mathrm{w})$ ratio. Addition of glass fiber in amount of $5 \%$ by weight of powder. An electronic digit balance was used with accuracy of $(0.0001 \mathrm{~g})$ as shown in Table (1). The fibers were added to the flexible acrylic powder then mixed and shaken well before mixing with the monomer (11).

Table (1):

Paired Samples Statistics of OPI scores before and after gargling

\begin{tabular}{|c|c|c|c|c|}
\hline \multirow{2}{*}{ Groups } & \multicolumn{4}{|c|}{ Proportioning } \\
\cline { 2 - 5 } & $\begin{array}{c}\text { Weight of } \\
\text { flexible } \\
\text { acrylic }\end{array}$ & $\begin{array}{c}\text { Weight of } \\
\text { glass fibers } \\
\text { powder }(\mathrm{gm})\end{array}$ & $\begin{array}{c}\text { Total weight } \\
\text { of the }\end{array}$ & $\begin{array}{r}\text { Amount } \\
\text { of the }\end{array}$ \\
\hline Control & 23.4 & mixture $(\mathrm{gm})$ & $\begin{array}{r}\text { liquid } \\
(\mathrm{ml})\end{array}$ \\
\hline $5 \%$ & 22.23 & 1.17 & 23.4 & 10 \\
\hline
\end{tabular}

Flexible acrylic resin was mixed according to the instructions of manufacturer. Mixing procedure was done by conventional method. Curing was done at $\left(74 \mathrm{C}^{\circ}\right)$ temperature for $(8)$ hours in water bath

\section{Finishing and polishing}

All the flexible acrylic resin specimens were finished by using sand paper sheet. While polishing was done by using bristle brush and pumice with dental lathe polishing machine using law speed (1500rpm). The abrasive paper was used with light pressure for all specimens. Pumice mixed with water at $1: 1$ ratio and used with a cloth wheel of $12.5 \mathrm{~mm}$ for 60sec. at 3,000 revolution per minute (RPM) on the lathe machine. Then fine grit pumice was used. High shine buff was used with polishing brown Tripoli ${ }^{12}$, ${ }^{13)}$. The specimens were conditioned in distilled water for two days at $37^{\circ} \mathrm{C}^{(14)}$. 


\section{Testing Procedure}

Instron testing machine was used for tensile test. It was equipped with suitable grips for holding the specimen. Set at cross head speed of $0.5 \mathrm{~mm}$./minute with a chart speed $(20 \mathrm{~mm} . / \mathrm{min}$.). The loads were analyzed by a tensile load cell with $100 \mathrm{Kg}$ a maximum capacity. The force at failure was measured in $\mathrm{kg}$ which were converted into (Newton $\mathrm{N}$ ) ${ }^{(15)}$. The values of tensile strength were calculated by the following formula ${ }^{(16)}$.

T.S. $=$ F/A

Where:-

T.S. = Tensile strength $\left(\mathrm{MPa}\right.$ or $\left.\mathrm{N} / \mathrm{mm}^{2}\right)$.

$\mathrm{F}=$ Force at failure $(\mathrm{N})$.

A $=$ Area of cross section at failure (mm).

\section{Modulus of elasticity:-}

\section{Surface roughness test}

Sample preparation for test: - (20 mm in diameter and $3 \mathrm{~mm}$ in thickness) ${ }^{(18)}$ (Fig. 4).

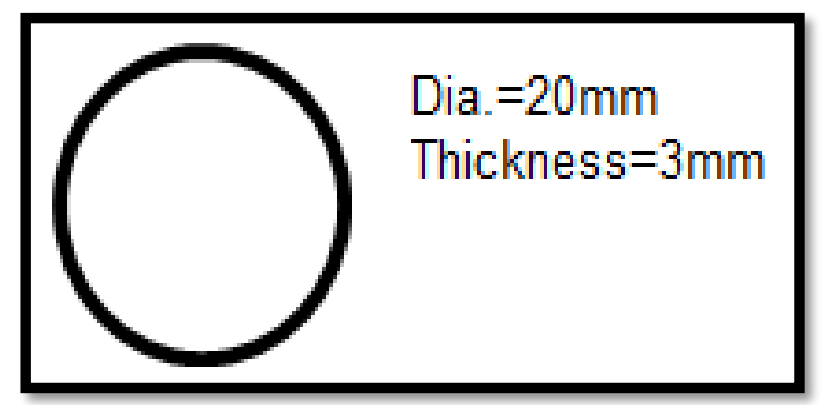

Figure (4): Dimensions of Roughness test Specimen.

Proportion, mixing, packing, curing, finishing, polishing and conditioning was done in the same procedure for tensile test (Fig 5,6$)$.

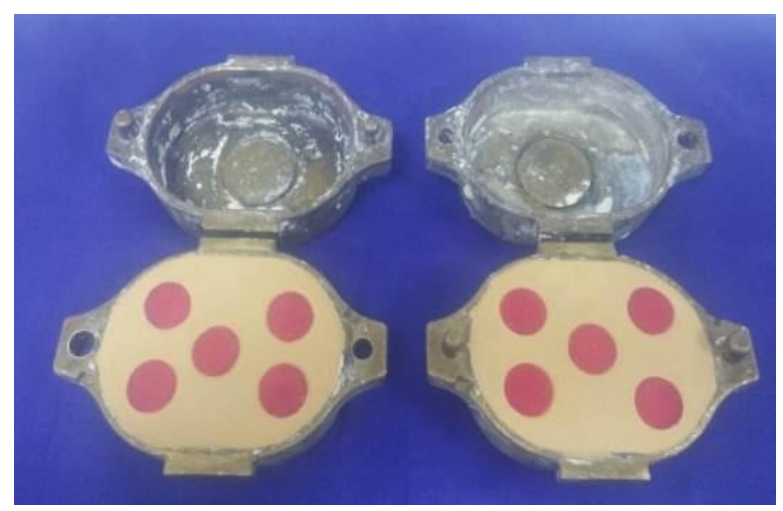

Figure (5): Specimen for roughness test.
The values of reading of modulus of elasticity test were gained from the tensile machine. The graphs of stress versus strain from the Tensile strength test were used. The modulus of elasticity was taken from the slope of the tangent drawn to the steepest initial straight line portion of the stress strain curve as in equation $\left({ }^{17)}\right.$.

\section{$E=P \times L / W \times d x I$}

Where:-

$\mathrm{E}=$ Modulus of elasticity $\left(\mathrm{MPa}\right.$ or $\left.\mathrm{N} / \mathrm{mm}^{2}\right)$.

$\mathrm{P}=$ Applied force $(\mathrm{N})$.

$\mathrm{L}=$ Original length of the specimen $(\mathrm{mm})$.

$\mathrm{W}=$ Width of specimen $(\mathrm{mm})$.

$\mathrm{d}=$ depth of specimen $(\mathrm{mm})$.

$\mathrm{I}=$ Increase in length $(\mathrm{mm})$. 


\section{Testing Procedure for Roughness test}

T.R. 200 device was used to test the roughness of the specimens which were placed on stable and fixed base then adjusted the device by making the stylus just touch the specimen surface. The stylus traversed toward the right direction along the specimen surface of $(11 \mathrm{~mm}$.) length at end. The reading appeared on the digital scale ${ }^{(11)}$.

\section{RESULTS}

\section{Tensile Strength Test Results}

As shown in table (2) Descriptive statistics which include (Mean, SD. Std error, min and max ).Tensile test values showed that the maximum mean values were in group of $(2.5: 1) \mathrm{p} / \mathrm{L}$ ratio with fibers addition $(248.399 \pm 12.3120-\mathrm{MPa})$, while the lowest mean values were in group of (3:1) powder-monomer ratio without fibers addition (200.867 \pm 15.1340 $\mathrm{MPa}$ ),

as shown at table (2) and Figure (7).

Table (2):

Descriptive statistic for tensile strength according to the studied groups.

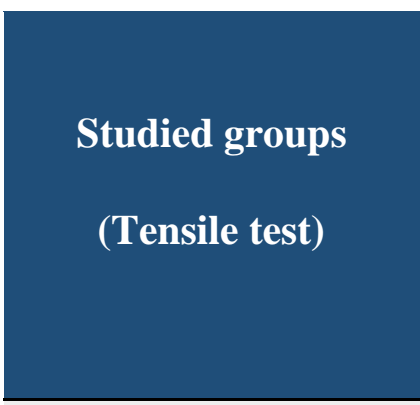

3:1 ratio without fiber

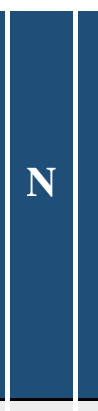

10

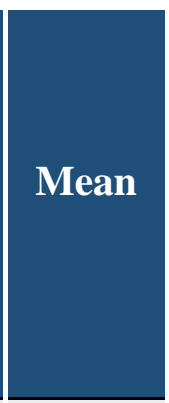

200.867

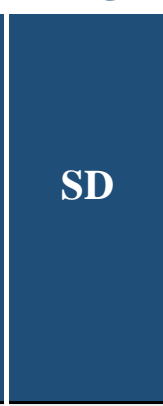

15.1340
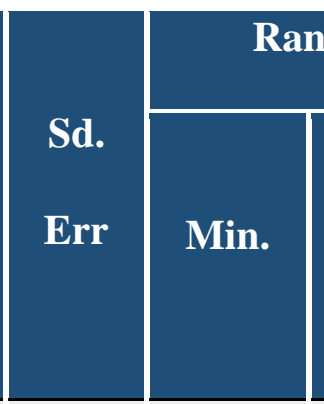

4.7858

180.180

225.859

\section{3:1 ratio with fiber \\ 2.5:1 ratio without fiber (control)}

10

229.333

28.5180

9.0182

180.737267 .981

10

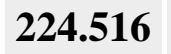

53.5492

16.934

171.396350 .089

$P=0.019$

2.5:1 ratio with fiber

$\begin{array}{ll}10 & 248.399\end{array}$

12.3120

231.033268 .212

\section{Total}

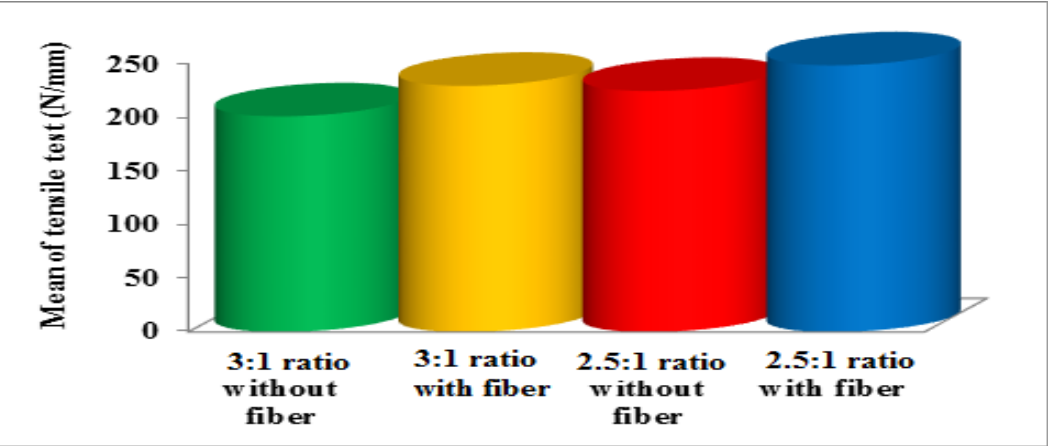

Figure (7): Descriptive statistic for tensile strength according to the studied groups. 
Least significant difference (LSD) test showed that significant differences at $(\mathrm{P}<0.05)$ was found between the group of (3:1) powder-monomer ratio without fibers addition and group of (3:1) ratio with fibers addition. Highly significant differences $(\mathrm{P}<0.01)$ was shown between $(3: 1)$ ratio without fibers addition and $(2.5: 1)$ ratio with fibers addition

groups. While non-sig difference $(\mathrm{P}>0.05)$ showed between $(3: 1)$ ratio and $(2.5: 1)$ ratio without fibers addition groups. Another non-sig difference $(\mathrm{P}>0.05)$ showed between (3:1) ratio with fibers addition groups when compared with the groups of $(2,5 ; 1)$ ratio with fibers addition. Finally, the ratio of (2.5:1) with and without fibers addition groups also showed non-significant differences as in table (3).

Table (3):

Multiple comparison test (LSD) of tensile strength between tested groups.

\begin{tabular}{|c|c|}
\hline \multicolumn{2}{|c|}{ Studied groups (Tensile test) } \\
\hline $3: 1$ ratio without fiber (control) & $3: 1$ ratio with fiber \\
\hline $3: 1$ ratio with fiber & $2.5: 1$ ratio without fiber \\
\hline $2.5: 1$ ratio without fiber & $2.5: 1$ ratio with fiber \\
\hline
\end{tabular}

Modulus of elasticity test results:

Modulus of elasticity values showed that the highest mean values were in different ratio without fibers addition group $(2.5: 1)$ ratio $(5939.624 \pm 1145.911 \mathrm{MPa})$, while the lowest mean values were in the control group (3:1) ratio without fibers addition $(5221.749 \pm 739.519 \mathrm{MPa})$ as shown in table (4) and figure (8).oneway ANOVA showed, non-sig differences at $(\mathrm{P}>0.05)$ between all the tested groups.

Table (4):

Descriptive statistic for modulus of elasticity according to the studied groups.

\begin{tabular}{|c|c|c|c|c|c|c|c|}
\hline \multirow{2}{*}{$\begin{array}{l}\text { Studied groups } \\
\text { (Modulus of } \\
\text { Elasticity test) }\end{array}$} & \multirow[b]{2}{*}{$\mathbf{N}$} & \multirow[b]{2}{*}{ Mean } & \multirow[b]{2}{*}{ SD } & \multirow{2}{*}{$\begin{array}{c}\text { St. } \\
\text { Error }\end{array}$} & \multicolumn{2}{|c|}{ Range } & \multirow{2}{*}{$\begin{array}{l}\text { ANOVA } \\
\text { test } \\
\text { P-(value) }\end{array}$} \\
\hline & & & & & Min. & Maxi. & \\
\hline 3:1 ratio without fiber & 10 & 5221.749 & 739.519 & 233.857 & 3859.696 & 6113.616 & \multirow{5}{*}{$\begin{array}{r}P=0.373 \\
\text { Non sign. } \\
(P>0.05)\end{array}$} \\
\hline $3: 1$ ratio with fiber & 10 & 5803.422 & 1052.428 & 332.807 & 4090.624 & 7204.464 & \\
\hline 2.5:1 ratio without fiber & 10 & 5939.624 & 1145.911 & 362.369 & 4256.992 & 8008.576 & \\
\hline 2.5:1 ratio with fiber & 10 & 5825.539 & 957.351 & 302.7408 & 4670.880 & 7714.368 & \\
\hline Total & 40 & & & & & & \\
\hline
\end{tabular}




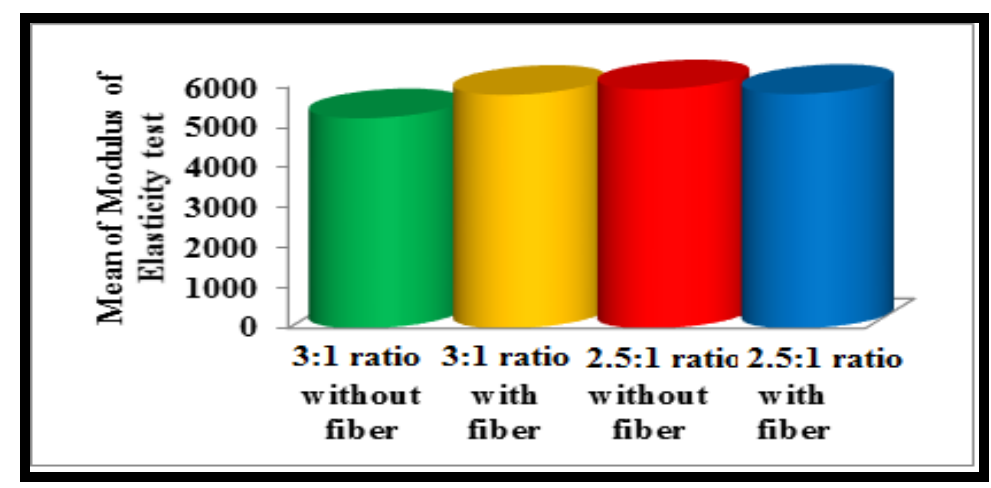

Figure (8): Descriptive statistic for modulus of elasticity.

\section{Surface roughness test results}

A- degree of surface roughness before polishing

The highest mean values were obtained in the specimens of different ratio with fiber addition (2.5:1) ratio (2.32090 \pm 0.040918$)$, while the smallest surface roughness values were obtained in specimens of $(3: 1)$ ratio with fibers addition (3.1) ratio (1.91640 \pm 0.001430$)$. (Table 5) and (figure 9). ANOVA test showed a highly sig at $(\mathrm{P}<0.01)$ between all the groups.

Table (5):

Descriptive statistic for surface roughness according to the studied groups before polishing

\begin{tabular}{|c|c|c|c|c|c|c|c|}
\hline \multirow{2}{*}{$\begin{array}{c}\text { Studied groups } \\
\text { (Roughness test }(\mu \mathrm{m}) \text { before polishing) }\end{array}$} & \multirow{2}{*}{$\mathbf{N}$} & \multirow{2}{*}{ Mean } & \multirow{2}{*}{ SD } & \multirow{2}{*}{$\begin{array}{l}\text { Std. } \\
\text { Error }\end{array}$} & \multicolumn{2}{|c|}{ Range } & \multirow{2}{*}{$\begin{array}{l}\text { ANOVA test } \\
\text { (P-value) }\end{array}$} \\
\hline & & & & & Mini. & Maxi. & \\
\hline 3:1 ratio without fiber & 10 & 2.19710 & 0.001197 & 0.000379 & 2.195 & 2.199 & \multirow{5}{*}{$\begin{array}{c}P \leq 0.001 \\
\text { Highly sign. } \\
(P<0.01)\end{array}$} \\
\hline 3:1 ratio with fiber & 10 & 1.91640 & 0.001430 & 0.000452 & 1.914 & 1.918 & \\
\hline 2.5:1 ratio without fiber & 10 & 2.31420 & 0.001874 & 0.000593 & 2.311 & 2.317 & \\
\hline 2.5:1 ratio with fiber & 10 & 2.32090 & 0.040918 & 0.012940 & 2.300 & 2.399 & \\
\hline Total & 40 & & & & & & \\
\hline
\end{tabular}

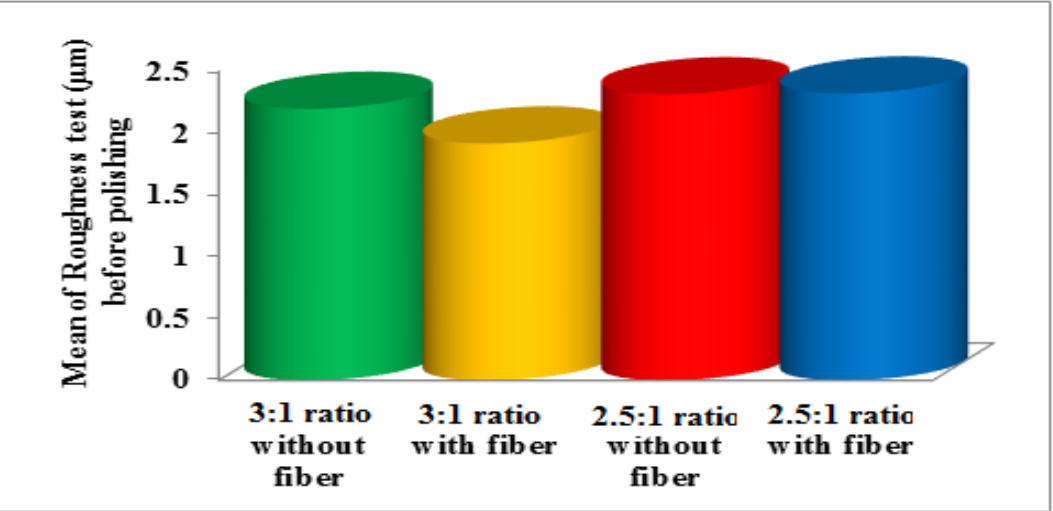

Figure (9): Descriptive statistic for surface roughness according to the studied groups before polishing.

LSD of multiple comparison test, revealed that HS differences at $(\mathrm{P} \leq 0.001)$ between most of the tested groups. The only non-significant $(\mathrm{P}>0.05)$ were observed between $(2.5: 1)$ ratio without fibers addition versus $(2.5: 1)$ ratio with fibers addition as shown in table (6). 
Table (6):

The results of multiple comparison test (LSD) of surface roughness between tested materials groups before polishing

\begin{tabular}{|c|c|c|}
\hline \multicolumn{2}{|c|}{ Studied groups (Roughness test ( $\mu \mathrm{m})$ before polishing) } & LSD test (P-value) \\
\hline \multirow{3}{*}{ 3:1 ratio without fiber } & 3:1ratio with fiber & $\begin{array}{c}P \leq 0.001 \text { H. sign. } \\
(P<0.01)\end{array}$ \\
\hline & 2.5:1 ratio without fiber & $\mathbf{P} \leq \mathbf{0 . 0 0 1} \mathrm{HS}$ \\
\hline & 2.5:1 ratio with fiber & $\mathbf{P} \leq \mathbf{0 . 0 0 1}$ HS. \\
\hline \multirow{2}{*}{ 3:1 ratio with fiber } & 2.5:1 ratio without fiber & $\mathbf{P} \leq \mathbf{0 . 0 0 1} \mathrm{HS}$ \\
\hline & 2.5:1 ratio with fiber & $\mathrm{P} \leq 0.001 \mathrm{HS}$ \\
\hline $2.5: 1$ ratio without fiber & $2.5: 1$ ratio with fiber & $\begin{array}{c}P=0.471 \text { Non sign. } \\
(P>0.05)\end{array}$ \\
\hline
\end{tabular}

\section{B. Degree of surface roughness after polishing}

The highest surface roughness mean values were obtained in specimens of (3:1 ratio) without fibers addition (0.42570 \pm 0.001059$)$, while the smallest mean values of surface roughness were obtained in the group of $(2.5: 1)$ ratio with fibers addition $(0.14610 \pm 0.001792)$. Table (7) and figure (10). ANOVA test observed highly sig differences $(\mathrm{P}<0.01)$ between tested the groups.

Table (7):

Descriptive statistic for surface roughness according to the studied groups after polishing.

\begin{tabular}{|c|c|c|c|c|c|c|c|}
\hline \multirow{2}{*}{$\begin{array}{c}\text { Studied groups } \\
\text { (Roughness test }(\mu \mathrm{m}) \text { after polishing) }\end{array}$} & \multirow{2}{*}{$\mathbf{N}$} & \multirow{2}{*}{ Mean } & \multirow{2}{*}{ SD } & \multirow{2}{*}{$\begin{array}{l}\text { Std. } \\
\text { Error }\end{array}$} & \multicolumn{2}{|c|}{ Range } & \multirow[b]{2}{*}{ (P-value) } \\
\hline & & & & & Min & $\max$ & \\
\hline $3: 1$ ratio without fiber & 10 & 0.42570 & 0.001059 & 0.000335 & 0.424 & 0.427 & \multirow{5}{*}{$\begin{array}{c}P \leq 0.001 \\
\text { Highly sign. } \\
(P<0.01)\end{array}$} \\
\hline 3:1 ratio with fiber & 10 & 0.25210 & 0.001101 & 0.000348 & 0.251 & 0.254 & \\
\hline 2.5:1 ratio without fiber & 10 & 0.31040 & 0.001776 & 0.000562 & 0.308 & 0.313 & \\
\hline 2.5:1 ratio with fiber & 10 & 0.14610 & 0.001792 & 0.000567 & 0.144 & 0.149 & \\
\hline Total & 40 & & & & & & \\
\hline
\end{tabular}

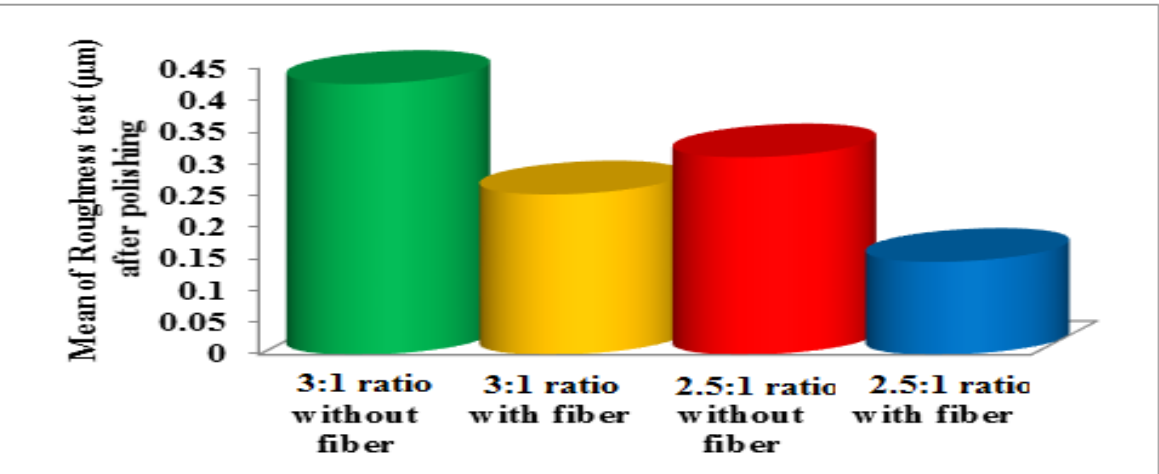

Figure (10): Descriptive statistic for surface roughness according to the studied groups after polishing.

LSD of multiple comparison test, showed maximum difference at $\mathrm{P}<0.01$ between all the groups as in table (8). 
Table (8):

The results of multiple comparison test (LSD) of surface roughness between tested materials groups after polishing.

\begin{tabular}{|c|c|c|}
\hline \multicolumn{2}{|c|}{$\begin{array}{l}\text { Studied groups (Roughness test ( } \mu \mathrm{m}) \\
\text { after polishing) }\end{array}$} & \multirow{4}{*}{ LSD test (P-value) } \\
\hline \multirow{3}{*}{ 3:1 ratio without fiber } & 3:1 ratio with fiber & \\
\hline & $2.5: 1$ ratio without fiber & \\
\hline & 2.5:1 ratio with fiber & \\
\hline \multirow{2}{*}{$3: 1$ ratio with fiber } & 2.5:1 ratio without fiber & \multirow{3}{*}{$P \leq 0.001$ Highly sign. $(P<0.01)$} \\
\hline & 2.5:1 ratio with fiber & \\
\hline 2.5:1 ratio without fiber & $2.5: 1$ ratio with fiber & \\
\hline
\end{tabular}

Student T-test as shown in table (9) revealed the mean values of surface roughness in $(\mu \mathrm{m})$ of $(3: 1)$ ratio without fibers addition before polishing (2.1971). Statistically, was highly value at $(\mathrm{P}<0.01)$ when compared with group of (3:1) ratio without fiber addition after finishing and polishing. There was a decrease in the mean of (3:1) ratio after polishing (0.4257) as illustrated in Figure (11).

Table (9):

T-test statistical analysis for 3:1 ratio with fiber before and after polishing.

\begin{tabular}{|c|c|c|c|c|c|c|c|c|}
\hline \multirow{2}{*}{\multicolumn{2}{|c|}{$\begin{array}{l}3: 1 \text { ratio without fiber } \\
\{\text { Roughness test }(\mu \mathrm{m})\}\end{array}$}} & \multirow{2}{*}{$\mathbf{N}$} & \multirow{2}{*}{ Mean } & \multirow{2}{*}{ SD } & \multirow{2}{*}{$\begin{array}{l}\text { Std. } \\
\text { Err }\end{array}$} & \multicolumn{2}{|c|}{ Range } & \multirow{2}{*}{ t- test } \\
\hline & & & & & & Min. & Max. & \\
\hline \multirow{2}{*}{ Polishing } & Before & 10 & 2.1971 & 0.00120 & 0.00038 & 2.20 & 2.20 & \multirow{3}{*}{$\begin{array}{c}P \leq 0.001 \\
\text { Highly } \\
\text { sign. }\end{array}$} \\
\hline & After & 10 & 0.4257 & 0.00106 & 0.00033 & 0.42 & 0.43 & \\
\hline \multicolumn{2}{|c|}{ Total } & 20 & & & & & & \\
\hline
\end{tabular}

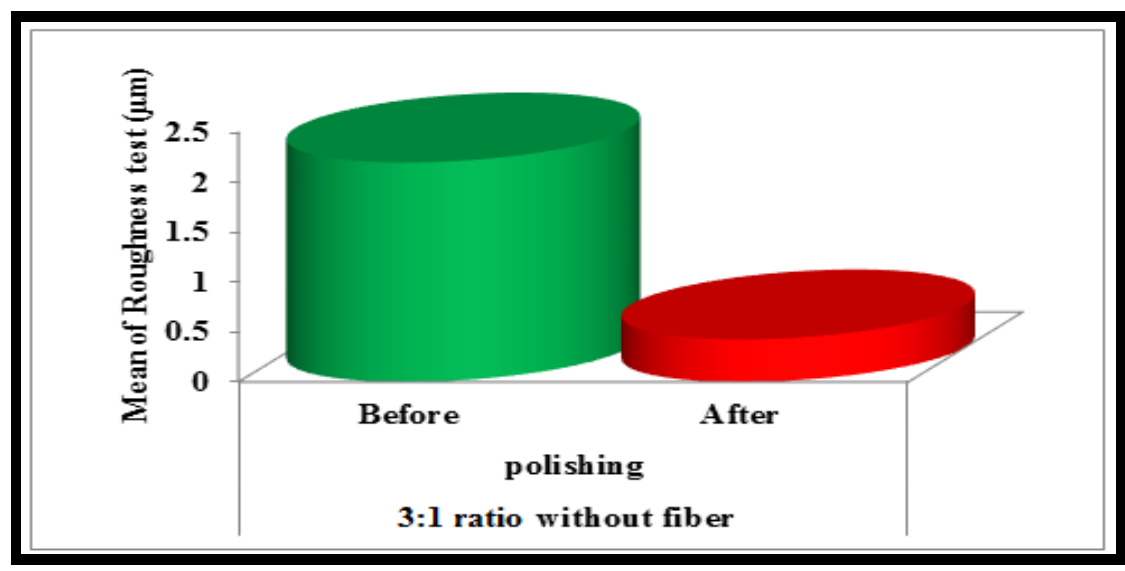

Figure (11): Mean value for 3:1 ratio without fiber for roughness test.

The differences between groups of (3:1) ratio with fibers addition showed maximum differences at $(\mathrm{P}<0.01)$ as showed in table $(10)$ and figure $(12)$. 
Table (10):

T-test statistical analysis for 3:1 ratio with fiber before and after polishing.

\begin{tabular}{|c|c|c|c|c|c|c|c|c|}
\hline \multirow{2}{*}{\multicolumn{2}{|c|}{$\begin{array}{l}\text { 3:1 RATIO with fiber } \\
\{\text { Roughness test }(\mu \mathrm{m})\}\end{array}$}} & \multirow{2}{*}{$\mathbf{N}$} & \multirow{2}{*}{ Mean } & \multirow{2}{*}{ SD } & \multirow{2}{*}{$\begin{array}{l}\text { Std. } \\
\text { Err. }\end{array}$} & \multicolumn{2}{|c|}{ Range } & \multirow{2}{*}{$\begin{array}{c}\text { t- test } \\
\text { (P-value) }\end{array}$} \\
\hline & & & & & & Min & Max & \\
\hline \multirow{2}{*}{ Polishing } & Before & 10 & 1.91640 & 0.001430 & 0.000452 & 1.914 & 1.918 & \multirow{2}{*}{$\begin{array}{c}\text { P } \leq \mathbf{0 . 0 0 1} \\
\text { Highly } \\
\text { sign. }\end{array}$} \\
\hline & After & 10 & 0.25210 & 0.001101 & 0.000348 & 0.251 & 0.254 & \\
\hline
\end{tabular}

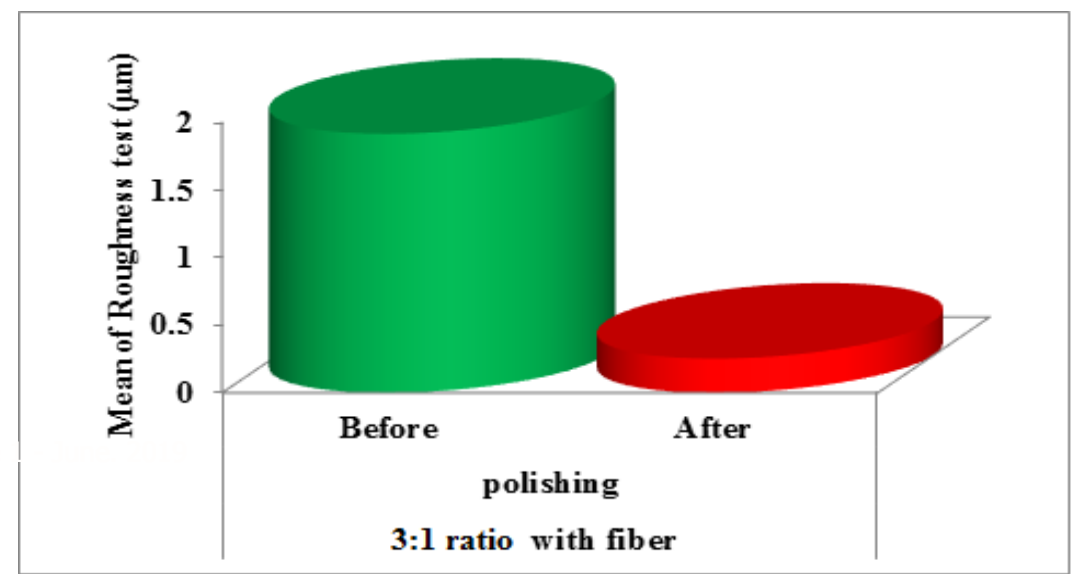

Figure (12): Mean value for 3:1 ratio with fiber before and after polishing for roughness test.

Specimens with (2.5:1) ratio also showed highly significant differences before and after polishing at $(\mathrm{P}<0.01)$ as in table (11) and figure (13).

Table (11):

T-test statistical analysis for 2.5:1 ratio without fiber before and after polishing.

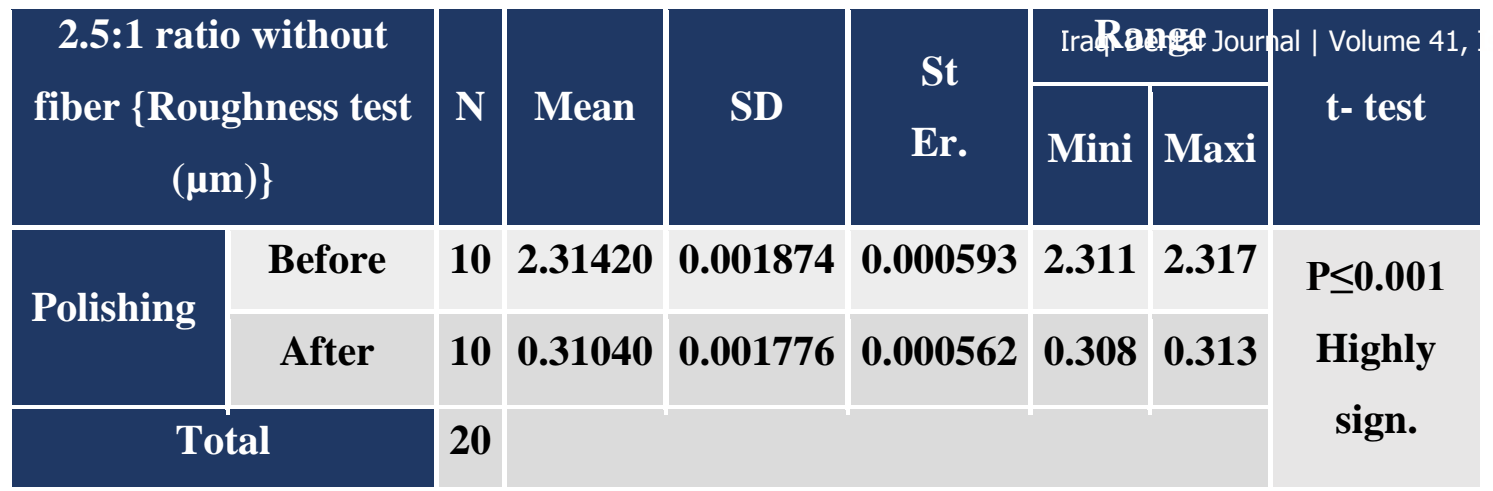

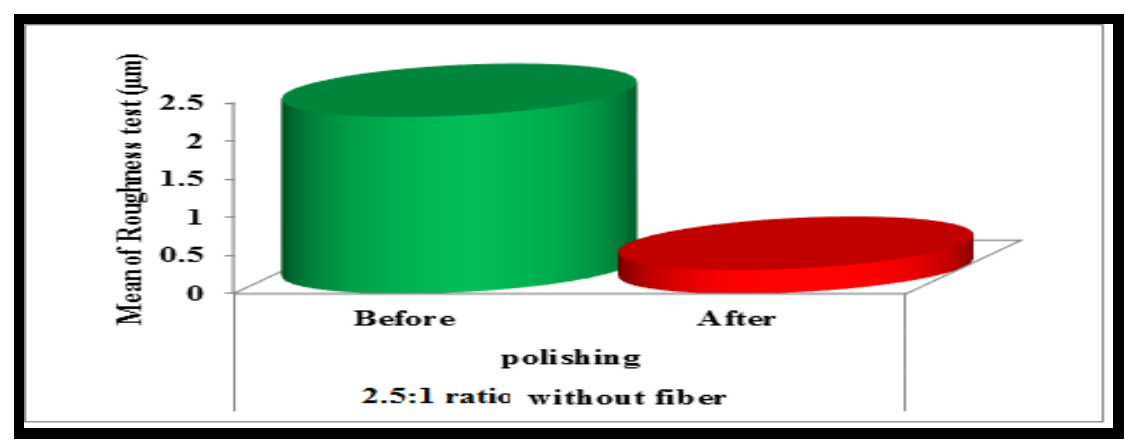

Figure (13): Mean value for 2.5:1 ratio without fiber before and after polishing for roughness test. 
Table (12) and figure (14) showed highly significant differences at ratio of (2.5:1) with fibers addition.

Table (12):

T-test statistical analysis for 2.5:1 ratio with fiber before and after polishing.

\begin{tabular}{|c|c|c|c|c|c|c|c|c|}
\hline \multirow{2}{*}{\multicolumn{2}{|c|}{$\begin{array}{l}2.5: 1 \text { ratio with fiber } \\
\{\text { Roughness test }(\mu \mathrm{m})\}\end{array}$}} & \multirow{2}{*}{$\mathbf{N}$} & \multirow{2}{*}{ Mean } & \multirow{2}{*}{ SD } & \multirow{2}{*}{$\begin{array}{l}\text { Std. } \\
\text { Err. }\end{array}$} & \multicolumn{2}{|c|}{ Range } & \multirow{2}{*}{ t- test } \\
\hline & & & & & & Min. & Max. & \\
\hline \multirow{2}{*}{ Polishing } & Before & 10 & 2.32090 & 0.040918 & 0.012940 & 2.300 & 2.399 & \multirow{3}{*}{$\begin{array}{c}P \leq 0.001 \\
\text { Highly } \\
\text { sign. }\end{array}$} \\
\hline & After & 10 & 0.14610 & 0.001792 & 0.000567 & 0.144 & 0.149 & \\
\hline \multicolumn{2}{|c|}{ Total } & 20 & & & & & & \\
\hline
\end{tabular}

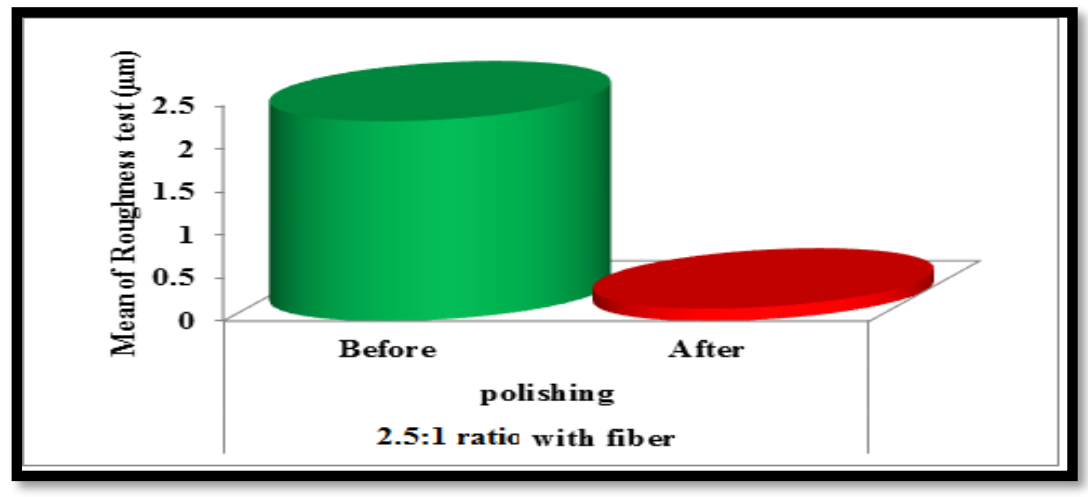

Figure (14): Mean value for 2.5:1 ratio with fiber before and after polishing for roughness test

\section{DISCUSSION}

The reinforcing effect of fibers on different polymer has been introduced to overcome the denture fracture by improving the properties of denture polymer. This study conducted to evaluate the influence of glass fibers on tensile strength, modulus of elasticity and surface roughness of flexible acrylic resin.

\section{Tensile and modulus of elasticity test}

Statistical analysis of the tensile test observed a significant difference in the flexible acrylic samples at 3:1 ratio groups with and without fiber glass addition, where adding the fibers seemed to increase the tensile strength of flexible acrylic [Table (3) and figure (7)]. This can be attributed to the number of the hydrogen bonds (secondary bonds) between the polymer chains and strength ${ }^{(19)}$. The weak polyamide secondary bonds permits these chains to slide past one to another at lower stresses within polymer mass. In a morphs polymer matrix test specimen, the neutral axis placed in the middle of the specimen. The neutral axis is moved directly toward the fiber layer when the specimen includes the reinforcing fiber and a morphs layer of polymer. Depending on the ratio between the homogeneous polymer layer and modulus of the fibers incorporated, the location of neutral axis even inside the fiber layer, can cause the weaker layer to be open to higher stresses while the fibers were more evenly distributed and filled the whole volume of the mold resulting in a homogenous structure ${ }^{(20)}$.

Flexibility (tensile and modulus of elasticity) is defined as the strain that occurs when the material is stressed to its proportional limit, this strain is important because it represents the percent deformation that can be sustained in a material before it becomes permanently damaged (18).this study showed significant differences in tensile strength only in 3:1 ratio without fibers addition when compared with $3: 1$ and 2.5:1 ratio with fibers addition while nonsignificant differences in all tested groups in modulus of elasticity this duo to statistically difference that all specimens tested in Instron testing machine, so the difference just between the equation of tensile test and modulus of elasticity test. 


\section{Surface Roughness Test:}

The roughed surface of polyamide may influence by some degree of disintegration of the surface which is heated to a temperature higher than of the Polymethylmethacrylate. The difference in Roughness area value ( $\mathrm{Ra}$ value) of polyamide polished surface was accounted highly significant. This due to the materials is differences in the physical properties. Fraying (well defined area)at the edges of the flexible specimens was noticed during polishing of the samples in this study which may have occurred due to exposed to higher temperature . The average of cooling of processed flexible affects the characteristics of surface properties and it has been mentioned that slow cooling results a relatively stiff material and strong but a rough surface table (5).

A smooth surface of the mold cavity would be beneficial to improve the quality of the surface of flexible where trimming is not necessary as in clasps. The pressure, temperature and the cooling rate has to be standardized for high qualities of the surface of the denture. Despite the acceptable Roughness area value of polished polyamide as in this study, it is noteworthy that the polishing of this material in lab practice would be performed in various conditions ex, polishing is not always performed flat surfaces and the recommended pressure of a rotating polisher and speed are difficult to control. Therefore, higher differences in roughness values may be expected in practice. Manufacturer's recommendations for flexible polyamide propose the material can be used as a framework of removable partial denture due to its flexural properties. In such circumstance, a lathe machine may not be capable to polish all parts of the clasps adequately also minor and major connectors. Further, investigations with the effect of interfacial media (liquid and polishing pastes), duration of motion, controlled load application and velocity are needed to improve the surface roughness of polyamides. Influence of polishing with fine diamond rubber cups under low speed pressure and the use of cooling system to minimize heat generation during polishing aid to be investigated ${ }^{(21)}$. In this study, the traditional polishing technique used for polymethyl acrylate provided a roughness area below the accepted threshold $\mathrm{Ra}$ value table $(7,8)$. The variation in $\mathrm{Ra}$ values of polished surfaces of flexible specimens was found to be statistically improved after glass fibers addition and polishing procedure, this may be contributed to use special tools (finishing burs) during polishing procedure.

\section{CONCLUSION}

We can conclude that:

1- The flexible acrylic resin specimens had significantly lower tensile strength at ratio of 3:1 without fibers addition when compared with ratio of 3:1 with fibers addition while non-significant differences were seen between samples used at ratios of 2.5:1 and 3:1 without or with fibers addition .

2- The modulus of elasticity according to the studied groups had no significant effect at ratio of $2.5: 1$ and $3: 1$ with and without fibers addition.

3- Flexible acrylic specimens showed significant improvement in surface roughness at 3:1 ratio with and without fibers addition when compared with $3: 1$ ratio with fibers addition and 2.5:1 with and without fibers addition and alteration in powder-liquid ratio except 2.5:1 ratio without fibers addition when compared with 2.5:1 with fibers addition before polishing while highly significant improved in surface roughness were showed between all tested groups and alteration in powder-liquid ratio after polishing so we encourage the author to use glass fibers and alteration in powder-liquid ratio .

\section{REFRENCES}

1. Khindria S.K., Sanjeer M., Urrashi S.: Evolution of denture base materials.J. ind. Prosthodont. SOCI,2009; 6(2) : 64-69.

2. Anusavice K.J: Phillips Science of dental materials. Eleventh edition, St. Louis : Saunders Company 2014; P: 143-70, 721-56.

3. Yuki KF, Satoru Naho HN: Bonding strength of auto polymerizing resins to nylon denture base polymer. J Dent Mat, 2009 ; 28(4) :409418.

4. Kuwahara K., Nagahama F., Kitahara K., Waka Makimura M., Kimura K., Sakamak H., Iudou J., Ogura K., Konayashi K. A case of using nonmetal clasp partial denture for the patient with the metal allergy. Nihon Univ. J. oral Sc. 2004; 30:134-139.

5. Farina AP, Cecchin D, Soares RG, Botelho AL, Takahashi JM, Mazzetto MO, Mesquita MF. Evaluation of Vickers hardness of different types of acrylic denture base resins with and 
without glass fiber reinforcement. Gerodontology ,2012; 29: 155-160.

6. Gad MM., Foudas M., AL-Harbi FA., Napankangasr., Rausta A. PMMA denture base material enhanced: a review of fiber, filler and Nano filler addition. Int. J. Nano medicine. 2017 ; 12: 3801-3812

7. Mccabe J.F. and Walls A.W.G. Applied dental material", John Wiley and sons, Black well scientific Publication, Oxford, London. 2013; pp.97-198.

8. Mehmood Asghar, Shhab UD Din,Muhammad Kaleem.Effect of incorporating two different woven glass fiber reinforcement on the flexural strength of acrylic denture base materials. Journal of dental science.2017; 51(1): pp20-28.

9. Mieszko Wieckiewicz,Volker Optiz, Gert Richer and Klaus W.Physical properties of Polyamide-12versus PMMA Denture Base Material.BioMed

Research International.2014:Article ID 150298,8 Pages.http://dx.doi.org/10.1155.

10. Hanna BA, ABD Al-Majeed AE,AbdulL Razak W.Effect of different dental Materials on the Surface Roughness of Acrylic Resin (Comparative in vitro study)MDJ.2008;5: pp281-85.

11. Gad M M., Rahoma A. and AI-Thobity A M. Effect of polymerization technique and glass fiber addition on the surface roughness and hardness of PMMA denture base material. Dental Materials J.2018;37(5):pp1-8.

12. Franklin P, Wood D.J., Bubb N.L.: Reinforcement of poly (methyl methacrylate) denture base with glass flake. Dent. Master.2005; 21:365-370.

13. Srividy S, Chandrasekharan K., Nair, Jayakar Shetty. Effect of Different Polishing Agents on Surface Finish and Hardness of Denture Base Acrylic Resins: A Comparative Study. International Journal of Prosthodontics and Restorative Dentistry. 2011; 11, 7-11.

14. Mahroo Vojdani A. Rashin Giti. Polyamide as a Denture Base Material: A Literature Review". J Dent Shiraz Univ Med Sci, 2015; 16:1-9.

15. Ayaz E. A., Bagis B., Turgut S. Effects of thermal cycling on surface roughness, hardness and flexural strength of polymethylmethacrylate and polyamide denture base resins. J Appl Biomater Funct Mater. 2015;13(3),p280-286.

16. Abu Anzeh M.I: "Evaluation of tensile bond strength of tooth denture base resin as a function of different surface treatments and processing regimes." M.Sc. Thesis University of Baghdad College of Dentistry 2003.pp1560.

17. Craig RG And Powers J M: Restorative dental materials. 2002;11 ${ }^{\text {th }}$ ed. St. Lois : Mosby.pp $65,118,215,243$.

18. Anusavice K.J: Philips science of dental material.1996; $11^{\text {th }}$ ed. Philadelphia : W.B. sanders Com. PP. 211-235, 237-271. Ch. 10 and 11 .

19. Lamis H. , Mohamed A. ELSharawy: Comparative study of surface roughness between polyamide, thermoplastic polymethyl methacrylate and acetal resins flexible. Life Science Journal .2015; 12, (10). Pp90-95.

20. O' Brien William J., PhD. Dental Material and their selection". $4^{\text {th }}$ edition, Oxford , Quintessence copyright .2008; P: 74-88.

21. Menaka A. Abuzar, Suman Bellur, Nancy Duong, Billy B. Kim , Priscilla LU, Nick Pallfreyman, Dharshan Surendran and Vinh T. Tran. Evaluating surface roughness of a polyamide denture base material in comparison with poly (methyl methacrylate ). Journal of oral science.2010; Vol. 52. No.4, 577-581. 